\title{
ANÁLISE SWOT DE UMA INDÚSTRIA METAL MECÂNICA DE PRESIDENTE PRUDENTE/SP.
}

\author{
Gustavo Yuho Endo, Murilo Gustavo Bott
}

Faculdade de Presidente Prudente - UNIESP, Presidente Prudente, SP. E-mail: gustavo endo@yahoo.com.br; murilo@equipamentosipiranga.com.br

\begin{abstract}
RESUMO
O estudo tem como objetivo aplicar a ferramenta estratégica Análise SWOT - Strengths (Forças), Weaknesses (Fraquezas), Opportunities (Oportunidades) e Threats (Ameaças) e, a partir dos resultados obtidos proporem intervenções para a indústria metal mecânica de Presidente Prudente/SP. A metodologia utilizada no estudo foi o relato técnico-científico sendo uma pesquisa aplicada que descreve uma experiência nas organizações e, descreve um processo de intervenção prática realizado em uma organização. Os resultados obtidos a partir da análise SWOT foi possível identificar que os pontos fracos são o catálogo de produtos e a marca; já os pontos fortes são a durabilidade, qualidade e ergonomia dos produtos; as ameaças identificadas foram a diminuição de licitações e a retração do mercado e, a única oportunidade identificada foi a consolidação da empresa no segmento. As propostas de intervenções foram baseadas no catálogo de produtos e a marca, visto a importância desses aspectos em relação a concorrência e, a ênfase que o diretor deu nesses dois aspectos.
\end{abstract}

Palavras-Chaves: Estratégia. Ferramenta Estratégica. Análise SWOT. Percepção. Intervenção.

SWOT ANALYSIS OF A MECHANICAL METAL INDUSTRY OF PRESIDENTE PRUDENTE/SP.

\begin{abstract}
The study aims to apply the strategic tool SWOT analysis - Strengths, Weaknesses, Opportunities and Threats and, from the results obtained, propose interventions for the mechanical metal industry of Presidente Prudente/SP. The metodology used in the study was the techinal-scientific report being na applied research that describes na experience in the organizations and, describe a process of practical intervention carried out in an organization. The results obtained from the SWOT analysis were able to identify that the weaknesses are the product catalog and the brand; already the strengths are the durability, quality and ergonomics of the product; the identified threats were the decrease of bids and the market downturn, and the only opportunity identified was the consolidation of the company in the segment. The proposals for interventions were based on the catalog of products and the brand, given the importance of these aspects in relation to competition, and the emphasis that the director gave in these two aspects.
\end{abstract}

Keywords: Strategy. SWOT Analysis. Strategic Tool. Perception. Intervention.

\section{INTRODUÇÃO}

As organizações necessitem elaborarem estratégias corporativas, na qual devem desenvolver um modelo de decisão para que seus objetivos e metas sejam alcançados, tendo em vista que, com a estratégia elaborada as organizações possam se precaverem de incertezas que possam vir a ocorrer no futuro e, objetivando obter vantagens competitivas em relação a concorrência (JOHNSON; SCHOLES; WHITTINGTON, 2011; BARNEY; HESTERLEY, 2007; MINTZBERG et. al., 2007). 
Diante da importância da formulação de estratégias, Dyson (2004, p. 633) apresenta a ferramenta estratégica análise SWOT, que tem o objetivo de "conectar fatores internos e externos". Ou seja, a análise SWOT tem como foco a análise dos ambientes externos e internos das organizações. Nogueira (2014, p. 46) corrobora dizendo que "o objetivo dessa análise é gerar informações importantes para tornar a organização mais consciente de suas possibilidades futuras".

Conforme exposto na Tabela 1, apresenta-se a matriz SWOT, na qual nota-se que o ambiente interno é composto pelos pontos fortes e fracos da organização, ou seja, são aspectos que a organização possui controle sobre esses aspectos. Já o ambiente externo é composto pelas ameaças e oportunidades, na qual a organização não possui controle sobre essas variáveis (NOGUEIRA, 2014).

Tabela 1 - Análise SWOT

\begin{tabular}{|c|c|c|}
\cline { 2 - 3 } \multicolumn{1}{c|}{} & Aspectos Positivos & Aspectos Negativos \\
\hline Ambiente Interno & Forças & Fraquezas \\
\hline Ambiente Externo & Oportunidades & Ameaças \\
\hline
\end{tabular}

Fonte: Nogueira (2014); Castor (2009); Mintzberg et. al. (2007); Dyson (2004).

Ainda na Tabela 1, nota-se os aspectos positivos, esses aspectos as organizações devem potencializar/maximizar e, os aspectos negativos na qual as organizações devem minimizarem ou desenvolverem tais aspectos (NOGUEIRA, 2014; CASTOR, 2009; MINTZBERG et. al., 2007; DYSON, 2004).

Diante deve breve contexto, esse estudo tem como objetivo aplicar a ferramenta estratégica Análise SWOT - Strengths (Forças), Weaknesses (Fraquezas), Opportunities (Oportunidades) e Threats (Ameaças) e, a partir dos resultados obtidos propor intervenções para a indústria metal mecânica de Presidente Prudente/SP.

\section{METODOLOGIA}

Para Biancolino et. al. (2012, p. 297) a "administração é, por natureza, de objetivo aplicado, uma vez que envolve estudos direcionados ao melhor funcionamento das organizações". $E$, como este estudo tem por finalidade um estudo aplicado, foi selecionado o relato técnico-científico, na qual Biancolino et. al. (2012, p. 297) define como o "produto final de um trabalho (pesquisa aplicada ou produção técnica) que descreve uma experiência nas organizações". Ainda Rojo e Walter (2014, p. 4) acrescentam que o relato técnico-científico "descreve um processo de intervenção prática realizado em uma organização".

O objetivo proposto nesse estudo é a junção de Biancolino et. al. (2012), na qual será descrita a percepção do ambiente interno e externo em relação a quatro principais concorrentes que competem diretamente com a empresa em estudo e, sob a visão de Rojo e Walter (2014), com base nas informações levantadas pelo empresário será apresentada propostas de intervenções objetivando a manutenção e aumento da competividade em relação a concorrência.

O entrevistado que participou do presente estudo possui pós-graduação em administração industrial, experiência de mais de 15 anos no segmento meta mecânico, a empresa na qual trabalha é familiar, o mesmo sendo a 3a geração que está dirigindo a organização, atualmente o mesmo ocupa o cargo de diretor, atuando principalmente na área comercial e de produção e operações. Diante da descrição do entrevistado, entende-se a relevância sobre sua percepção em relação a concorrência e sobre o segmento em estudo.

Para o presente estudo foram selecionados quatro concorrentes que, de acordo com a percepção do entrevistado, o mesmo julgou pela sua experiência e vivência no segmento de metal mecânica, sendo que esses quatros são concorrentes diretos seja a nível nacional e regional e, 
assim, destacando a importância de realização da análise SWOT em relação a esses concorrentes e, por fim, apresentar propostas de intervenções, na qual o objetivo será maximizar o pontos fortes e oportunidades e, minimizar ou aprimorar os pontos fracos e a ameaças em relação a esses concorrentes.

Salienta-se a importância na qual os resultados obtidos foram extraídos a partir da percepção do entrevistado, em nenhum momento da pesquisa utilizou se de juízo de valor em relação aos resultados, uma vez que não é o foco do presente estudo. No presente estudo é valorizado a percepção do entrevistado pela sua vivência e experiência no segmento metal mecânico.

\section{RESULTADOS}

O presente estudo segue os pressupostos apresentados por Johnson, Scholes e Whittington (2011, p. 103) na qual a análise SWOT "somente se mostra útil se for comparativa - se examinar forças, fraquezas, oportunidades e ameaças em relação aos competidores". Sendo assim, o diretor que participou da pesquisa, elencou quatro concorrentes diretos de sua organização e, foi questionado quais são os pontos forte e fracos, as ameaças e oportunidades em relação aos quatro concorrentes.

$\mathrm{Na}$ Tabela 2 são apresentados os pontos fortes, os pontos fracos, as oportunidades e as ameaças em relação ao concorrente I, com base na percepção do entrevistado participante do presente estudo.

Tabela 2 - Análise SWOT do Concorrente I.

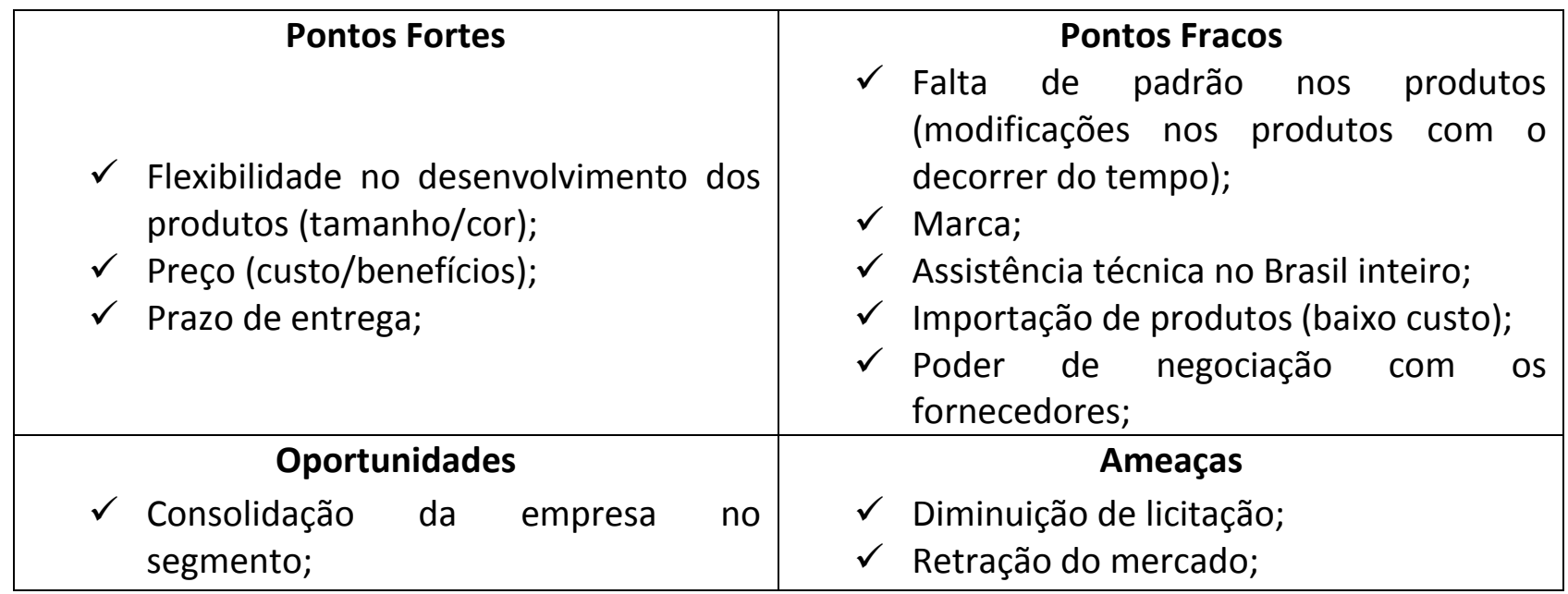

Fonte: Dados da pesquisa (2017).

$\mathrm{Na}$ Tabela 3 são apresentados os pontos fortes, os pontos fracos, as oportunidades e as ameaças em relação ao concorrente II, com base na percepção do entrevistado participante do presente estudo.

Tabela 3 - Análise SWOT do Concorrente II.

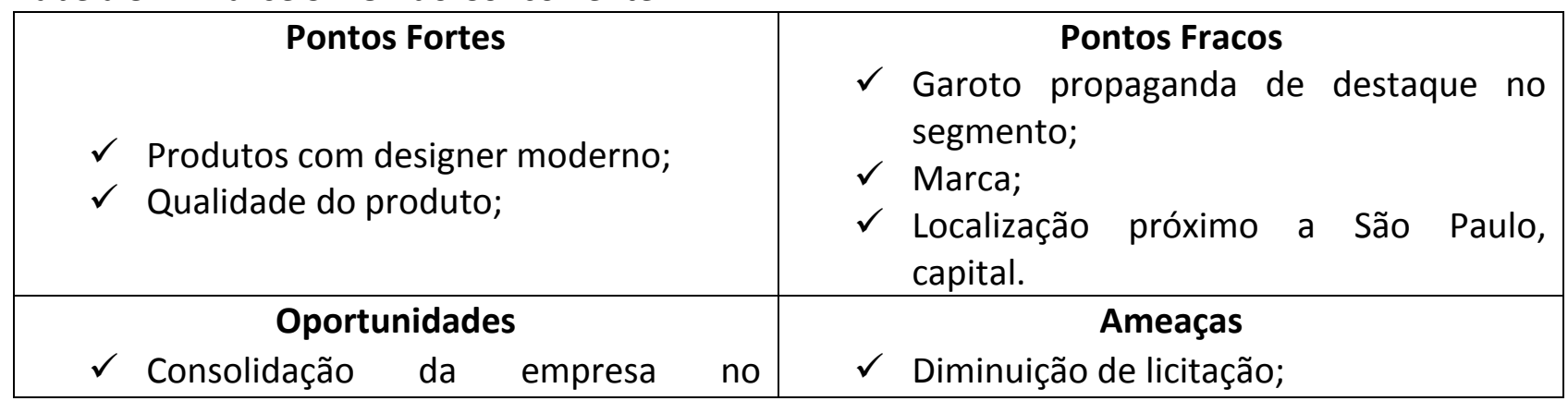

Colloquium Socialis, Presidente Prudente, v. 01, n. Especial 2, Jul/Dez, 2017, p.550-555. DOI: 10.5747/cs.2017.v01.nesp2.s0191 
Fonte: Dados da pesquisa (2017).

$\mathrm{Na}$ Tabela 4 são apresentados os pontos fortes, os pontos fracos, as oportunidades e as ameaças em relação ao concorrente III, com base na percepção do entrevistado participante do presente estudo.

Tabela 4 - Análise SWOT do Concorrente III.

\begin{tabular}{|c|c|}
\hline Pontos Fortes & Pontos Fracos \\
\hline $\begin{array}{ll}\checkmark & \text { Durabilidade do produto; } \\
\checkmark & \text { Ergonomia; } \\
\checkmark & \text { Credibilidade no mercado; } \\
\checkmark & \text { Atração de lojista que pertenciam a } \\
& \text { esse concorrente; }\end{array}$ & $\begin{array}{l}\checkmark \text { Catálogo de produtos (qualidade } \\
\text { superior); } \\
\checkmark \text { Variedades de linhas de produtos; } \\
\checkmark \text { Preço baixo; }\end{array}$ \\
\hline Oportunidades & Ameaças \\
\hline $\begin{array}{l}\checkmark \text { Consolidação da empresa } \\
\text { segmento; }\end{array}$ & $\begin{array}{ll}\checkmark & \text { Diminuição de licitação; } \\
\checkmark & \text { Retração do mercado; }\end{array}$ \\
\hline
\end{tabular}

Fonte: Dados da pesquisa (2017).

$\mathrm{Na}$ Tabela 5 são apresentados os pontos fortes, os pontos fracos, as oportunidades e as ameaças em relação ao concorrente IV, com base na percepção do entrevistado participante do presente estudo.

Tabela 5 - Análise SWOT do Concorrente IV.

\begin{tabular}{|c|c|}
\hline Pontos Fortes & Pontos Fracos \\
\hline $\begin{array}{ll}\checkmark & \text { Durabilidade do produto; } \\
\checkmark & \text { Ergonomia; }\end{array}$ & $\begin{array}{ll}\checkmark & \text { Marca; } \\
\checkmark & \text { Catálogo de produtos (qualidade } \\
& \text { superior); } \\
\checkmark & \text { Estética dos produtos superior; }\end{array}$ \\
\hline Oportunidades & Ameaças \\
\hline $\begin{array}{l}\checkmark \text { Consolidação da empresa no } \\
\text { segmento; }\end{array}$ & $\begin{array}{l}\checkmark \text { Diminuição de licitação; } \\
\checkmark \text { Retração do mercado; }\end{array}$ \\
\hline
\end{tabular}

Fonte: Dados da pesquisa (2017).

No próximo tópico serão apresentadas as discussões em relação aos resultados encontrados nesse estudo e, partir desses resultados será apresentado as propostas de intervenções.

\section{DISCUSSÃO}

Após a apresentação e análise dos resultados obtidos em relação aos concorrentes I, II, III e IV; este tópico tem como objetivo apresentar as propostas de intervenções, na qual a organização em estudo possa se prevenir de potenciais acontecimentos que o ambiente interno e externo possa oferecer.

Finalizado a análise SWOT da empresa em estudo em relação aos seus quatro principais concorrentes, identificou-se que os pontos fracos da empresa em estudo em relação a esses quatro concorrentes são: a marca e o catálogo de produtos, entende-se que ambos são pontos fracos em relação aos concorrentes em virtude dos dois aspectos se apresentarem em duas análises SWOT em relação aos seus concorrentes e, a preocupação do entrevistado em relação a marca de sua empresa. 
Em relação aos pontos fortes, foram identificados que a durabilidade, a qualidade e a ergonomia do produto oferecido são os aspectos que sobressaem em relação a concorrência, entretanto, conforme salientado pelo diretor, são características que a empresa possui dificuldade em demonstrar esse valor para seus clientes, fator esse que pode comprometer uma venda.

Sobre o ambiente externo, ou seja, as ameaças e oportunidades, na percepção do diretor todos os aspectos identificados vale para todos os concorrentes citados. As ameaças identificadas foram a diminuição de licitação, ou seja, com a diminuição das licitações houve decréscimo no faturamento das empresas, situação essa que está fora de controle das organizações em estudo. Outra ameaça identificada pelo diretor foi, diante do cenário econômico e político vivido pelo País, ocorreu a retração do mercado e, consequentemente, diminuíram se as vendas e juntamente com isso houve decréscimo no faturamento das organizações.

A única oportunidade identificada pelo diretor foi a consolidação da empresa no segmento, ou seja, a empresa conseguindo superar a retração do mercado ela estará se fortalecendo em seu segmento, o que em médio e longo prazo possa obter retornos acima dos seus concorrentes.

Após o brainstorming entre os pesquisadores e o diretor são apresentadas na Tabela 6 as propostas de intervenções para a empresa objeto do presente estudo.

Tabela 6 - Propostas de Intervenções

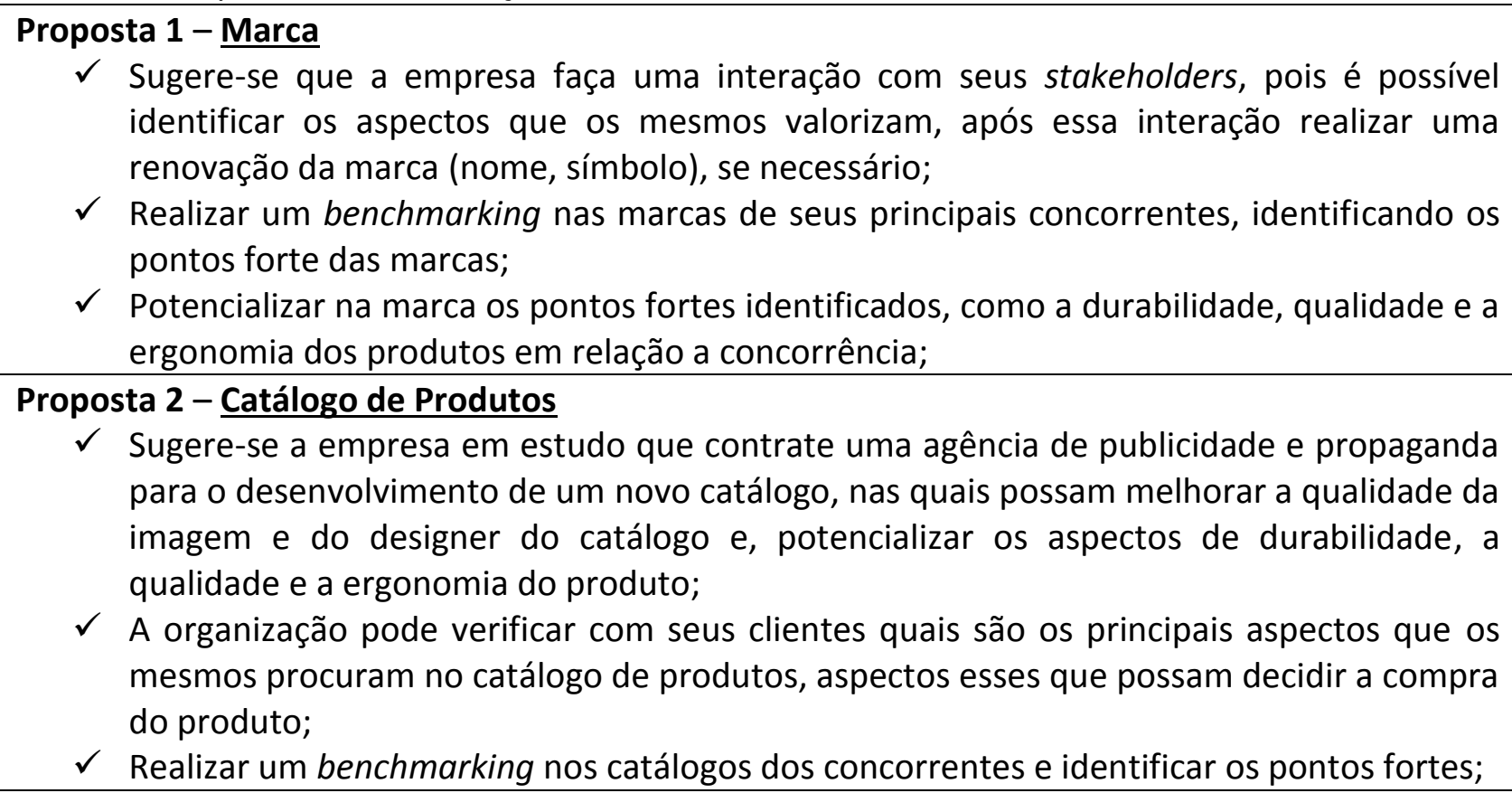

Fonte: Elaborado pelos autores (2017).

Por fim, fecha-se esse tópico com base nas análises SWOT em relação aos quatro concorrentes, foram propostas intervenções nas quais objetiva-se potencializar/maximizar os pontos fortes e oportunidades identificadas e, minimizar/desenvolver os pontos fracos e as ameaças identificadas. No próximo tópico, são apresentadas as considerações finais do estudo, juntamente com a limitações e as propostas para estudos futuros.

\section{CONSIDERAÇÕES FINAIS}

Os resultados obtidos a partir da análise SWOT foi possível identificar que os pontos fracos são o catálogo de produtos e a marca; já os pontos fortes são a durabilidade, qualidade e ergonomia do produto; as ameaças identificadas foram a diminuição de licitações e a retração do mercado e, a única oportunidade identificada foi a consolidação da empresa no segmento. As 
propostas de intervenções foram baseadas no catálogo de produtos e a marca, visto a importância desses aspectos em relação a concorrência e, a ênfase que o diretor deu nesses dois aspectos. Nesse sentido, entende-se que o objetivo proposto neste estudo foi alcançado.

Entende-se como limitação do estudo (i) ter participado da pesquisa somente um diretor, as informações geradas são de acordo com a percepção desse indivíduo; (ii) não houve um consenso entre a empresa participantes e os concorrentes I, II, III e IV em relação aos pontos levantados; (iii) as propostas de intervenções não foi possível acompanhar, se o diretor as colocou em prática e, se obteve os retornos esperados; (iv) a aplicação somente da ferramenta estratégica análise SWOT.

Por fim, entende-se como proposta para trabalhos futuros: (i) convidar outros indivíduos que possam corroboram com o diretor no levantamento das informações; (ii) convidar os concorrentes I, II, III e IV a participarem do estudo, contribuindo com suas percepções e, podendo gerar um estudo se aprofundando mais no segmento na qual essas organizações se situam; (iii) propor um estudo longitudinal, na qual seja possível acompanhar as propostas de intervenções e apurar se seus resultados foram positivos e, caso os resultados sejam negativos verificar quais os motivos; (iv) aplicar outras ferramentas estratégicas como a matriz BCG, Business Model Canvas e simulação de cenários.

\section{REFERÊNCIAS BIBLIOGRÁFICAS}

BARNEY, Jay B.; HESTERLY, William S. Administração estratégica e vantagem competitiva. São Paulo: Pearson Prentice Hall, 2007.

BIANCOLINO, César A.; et al. Protocolo para elaboração de relatos de produção técnica. Revista de Gestão e Projetos, v. 3, n. 2, p. 294-307, 2012.

CASTOR, Belmiro V. J. Estratégias para pequena e média empresa. São Paulo: Atlas, 2009.

DYSON, Robert G. Strategic development and SWOT analysis at the University of Warwick. European Journal of Operational Research, v. 152, n.3, p. 631-640, 2004.

JOHNSON, Gerry; SCHOLES, Kevan; WHITTINGTON, Richard. Fundamentos de estratégia. Porto Alegre: Bookman, 2011.

MINTZBERG, Henry; et al. O processo de estratégia: conceitos, contextos e casos. Porto Alegre: Artmed, 2007.

NOGUEIRA, Cleber S. Planejamento estratégico. São Paulo: Pearson Education do Brasil, 2014.

ROJO, Claudio A.; WALTER, Silvana A. Relato técnico: roteiro para elaboração. Revista Competitividade e Sustentabilidade, v.1, n.1, p. 1-18, 2014. 